\title{
Cybersecurity challenges in energy sector (virtual power plants) - can edge computing principles be applied to enhance security?
}

\author{
Sampath Kumar Venkatachary ${ }^{1 *} \mathbb{D}$, Annamalai Alagappan ${ }^{2}$ and Leo John Baptist Andrews ${ }^{3}$
}

\author{
* Correspondence: \\ sampathkumaris123@gmail.com; \\ sampathkumaris123@outlook.com \\ ${ }^{1}$ Grant Thornton, Plot 50370, \\ Acumen Park, Fairgrounds, \\ Gaborone, Botswana \\ Full list of author information is \\ available at the end of the article
}

\begin{abstract}
Distributed generators (D.G.'s) enable us to generate, supply and be self-reliant on power while also allows us to supply power to meet the demand through virtual power plants. The virtual power plants also help us analyse, control, optimise, and help bridge the gap of demand and supply in these vast energy requirements. With this also comes challenges associated with securing physical systems, data protection and information privacy. Recent technological advancements have aided cybercriminals to disrupt operations by carrying out deliberate attacks on the energy sector. Though security researchers have tried to mitigate the risks, vulnerabilities, and it remains a challenge. This paper aims to present a comprehensive Edge-based security architecture to help reduce the risks and help secure the physical systems and ensure privacy and data protection.
\end{abstract}

Keywords: Edge computing, Virtual power plants (VPP), Distributed energy resource (DER), Security architecture, IDS, Authentication and authorisation, Privacy

\section{Introduction}

Virtual Power Plants (VPP), Smart Grids (S.G.). Virtual Power Plant, "As its name infers, a virtual power plant does not exist in the solid and-turbine sense. It utilises the smart grid infrastructure to integrate little, divergent energy assets as though they were a single generator. Pretty much any energy source can be connected up. (Kumagai, 2012). Moreover, the energy can likewise add to a virtual power, not plant's capacity" The point of VPP's is to distributed appropriated energy assets over the virtual energy pool. (Fig. 1) shows a brief overview of a Virtual Power Plant. Unlike traditional energy systems, the energy generation is not centralised in a remote location and then transmitted in a complex network but instead generated in small individual distributed areas. In this, a consumer can become a prosumer and supply the excess energy generated back to the grid. The traditional model, though, is cost-effective the outreach of the model in third world countries pose a problem where the majority of the population have no access to energy. This problem technically can be addressed by using

(c) The Author(s). 2021 Open Access This article is licensed under a Creative Commons Attribution 4.0 International License, which permits use, sharing, adaptation, distribution and reproduction in any medium or format, as long as you give appropriate credit to the original author(s) and the source, provide a link to the Creative Commons licence, and indicate if changes were made. The images or other third party material in this article are included in the article's Creative Commons licence, unless indicated otherwise in a credit line to the material. If material is not included in the article's Creative Commons licence and your intended use is not permitted by statutory regulation or exceeds the permitted use, you will need to obtain permission directly from the copyright holder. To view a copy of this licence, visit http://creativecommons.org/licenses/by/4.0/. 


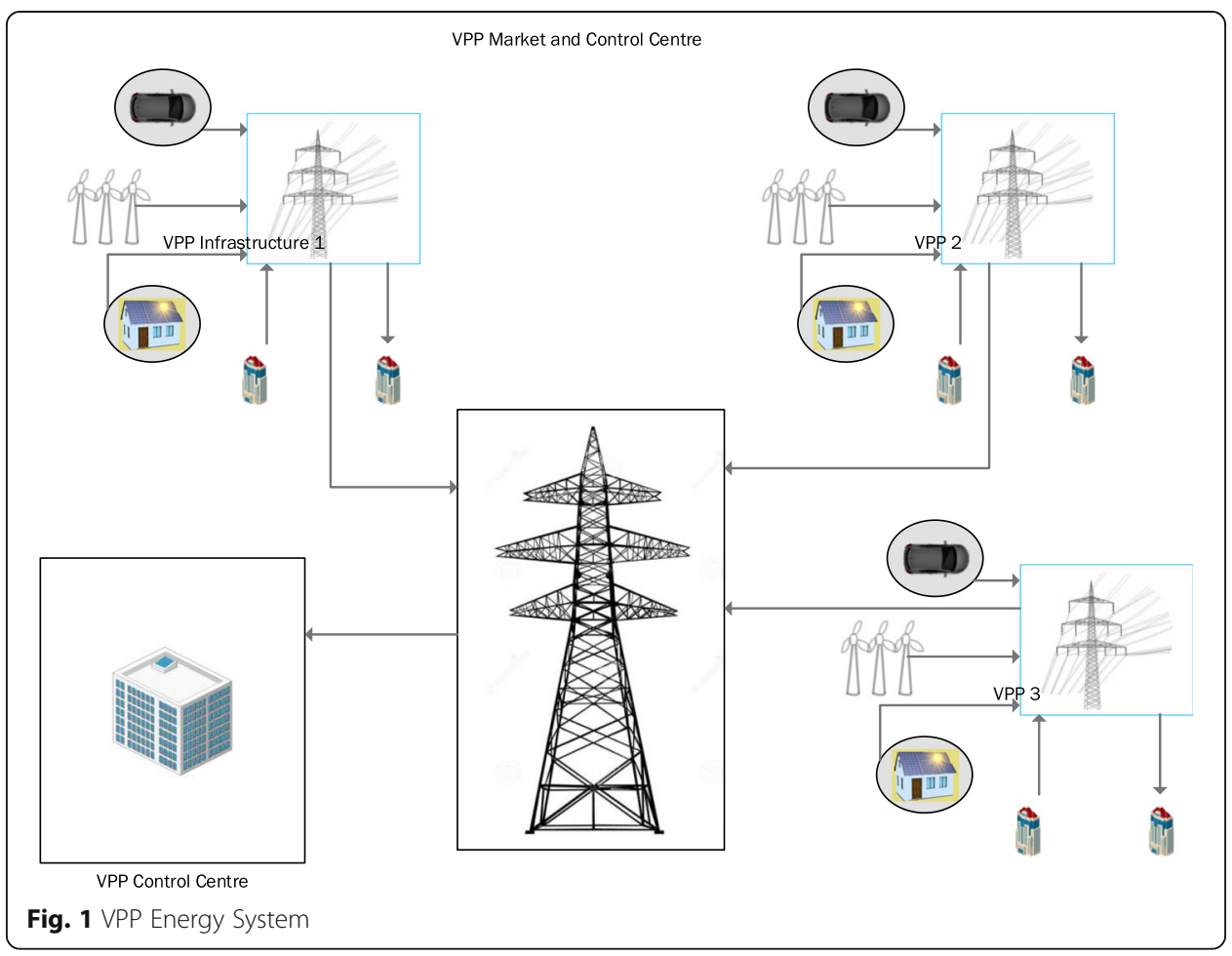

distributed energy networks and effectively exercise control through a VPP operator. It is expected that by $2035-2040$ the electricity system will mostly constitute decentralised IoT devices effectively communicating through virtual power plants and distributed energy systems. In short, electricity will be digital.

This growing deployment of small prosumers also poses a problem in the grid systems which also needs to adopt a decentralised approach to reduce the complexity and overcome the increasingly new challenges in management (Pop et al., 2019). These deployments pose a different set of problems in the form of efficiency in integration, energy supply security, continuity. Assuming the energy generated is not consumed by the consumer in the resource, it could also technically lead to over-voltage problems, losses, transformer ageing and efficiency.

The future energy networks will relate to advance distribution and management systems, including using data relating to grid monitoring, control, sensors, load balancing requirements, environmental parameters etc. (Rennie, 2019). The range of data shared between transmission and distribution, system, grid operators, consumers, prosumers, aggregators are enormous. Most of these systems will also be using intelligent control systems, distributed intelligence employing A.I. This will also help enhance consumers with improving capabilities, reporting and managing infrastructure.

\section{Edge virtual power plants}

The term edge computing is relatively a new concept, though very similar to other computing terminologies in use. Edge computing refers to simple process operations 
carried out close to the origins of data. In simple terms, the processes can be done on the devices rather than on the servers, increasing the processing speed. Therefore, it is possible to offload a few resource-hungry tasks to the new edge layer, thereby reducing the impact on resource-constrained resources. The application of edge technology in virtual power plant technically involves optimising resources through machine learning algorithms. As more and more DER systems integrate, the data must be processed balloons, requiring more processing power. Since each of these devices communicates with the IoT devices in the household, the information processed can be done locally (Rennie, 2019).

Traditional VPP's mostly are controlled centrally, and the information is collated and transmitted to these central units through a communication environment including 5G technologies (Jaber et al., 2016; Khodashenas et al., 2016) (Zaho \& Gerla, 2019). 5G communication technologies are said to noted to have privacy issues in a centralised environment (Cai et al., 2019; Cai \& Zheng, 2019; Tian et al., 2019), leading researchers to suggest distributed control methods (Chen et al., 2018a, b, c; Cai \& He, 2019; Huang et al., 2019). The advancement of technology has also led to research on edge computing for processing information and control. (Chen et al., 2018a, b, c; Chen et al., 2018a, b, c). The rise of A.I. and cognitive computing (Chen et al., 2019) has paved the way for applying mathematical tools to improve processes and efficiency, which are popularly termed as Edge Intelligence (Zhou et al., 2019; Rausch \& Dustdar, 2019). Due to this huge demand for processing on the edge nodes, edge computing applies the A.I. to enhance the processing speeds. The application of edge intelligence computing requires a huge communication network and bandwidth. As VPP is also a combination of distributed networks, some of these problems apply. Some of these problems have been effectively addressed to minimise the costs and reduce the communication environment by $\mathrm{Li}$ et al. (Li et al., 2018).

These dependencies on the ICT infrastructure also has potential cybersecurity threats. Since the operations are widespread and network-based with individual endpoints, the attack surface in a virtual power plant is vast since the core of the processes is from the control centre. The threat actors multiply manifold due to the different RTUs and SCADA gadgets. Any vulnerability in a single system is a gateway for hackers to get into the network. It can be noticed from the data analysed that the critical infrastructure services are frequently being targeted with malware or ransomware with a motive for financial gain or disruption. (Venkatachary et al., 2017; Venkatachary et al., 2018a; Venkatachary et al., 2018b). They are thus providing a way for enhancing security mechanisms across the network. Therefore, this new edge concept also offers the opportunity to deploy new based security solutions on the end devices, thus optimising performance. (Montero et al., 2016; Mach et al., 2017; Errabelly et al., 2017; Tao et al., 2017; Hsu et al., 2018).

Against this backdrop, this paper aims to provide an insight into various cybersecurity threats that emanate from these advance technological applications. Section 2 provides a detailed insight into cybersecurity trends and facilities attacked, and the need for better security. Section 3 discusses at length the proposed Edge-based solutions towards enhancing security in virtual power plants. Section 4 and 5 provides a detailed discussion and conclusions. 


\section{Cybersecurity trends and the edge centric architecture for VPP}

Among the sectors, the energy sector is one of the most targeted sectors in recent times. The motivation of the attackers has changed over time. Though the primary motivation still remains money, other motivations like cyber warfare and causing disruptions have also witnessed an increase Figs. 2 \& 3, and Table 1 outlines the basis and the sectors targeted. As can be seen, the trends during 2020 have changed an increase in health care facilities being targeted more than other industries. Given the vulnerabilities in the firmware of different types of equipment and addressing the vulnerabilities through patch mechanisms a nightmare for security firms, the energy sector is a primary motivator for cyber-attacks. According to data by Kaspersky labs, the attack vectors included DDos, Java Script, BAT, V.B. Script, Python, Word on the platforms (Kaspersky Labs, 2020).

The traditional approaches to handling cybersecurity using firewalls and cryptography incidents are outmoded due to the variety and complexity of attacks in recent times. The complexity of cybersecurity attacks in the form of disabling, tampering, reprogramming the control systems can lead to malfunctions, unavailability of system services during critical operations, which could lead to other consequences in the form of human life. (Venkatachary et al., 2018a; Venkatachary, 2018b; Venkatachary et al., 2020) In short, the cybersecurity attacks in the recent past has undergone a sea change. Some notable examples are black energy, Stuxnet and so on (Symantec, 2009; Symantec, 2011; Liu et al., 2012).

\section{Overview of cyber attacks and the need for better security to secure energy systems}

With the rise in energy demand, the distributed generators play a vital role in bridging the gap between demand and supply, securing the devices gain prominence. Security in device controllers is often overlooked as it is mostly isolated and tied to the infrastructure. This poses a problem of often not getting the control devices patched, thereby exposing them to vulnerabilities and attacks. An underlying problem in securing devices is the responsibility attached to the person. Often, it is found that most operators operating these machines simply do not have the experience or expertise and the knowledge

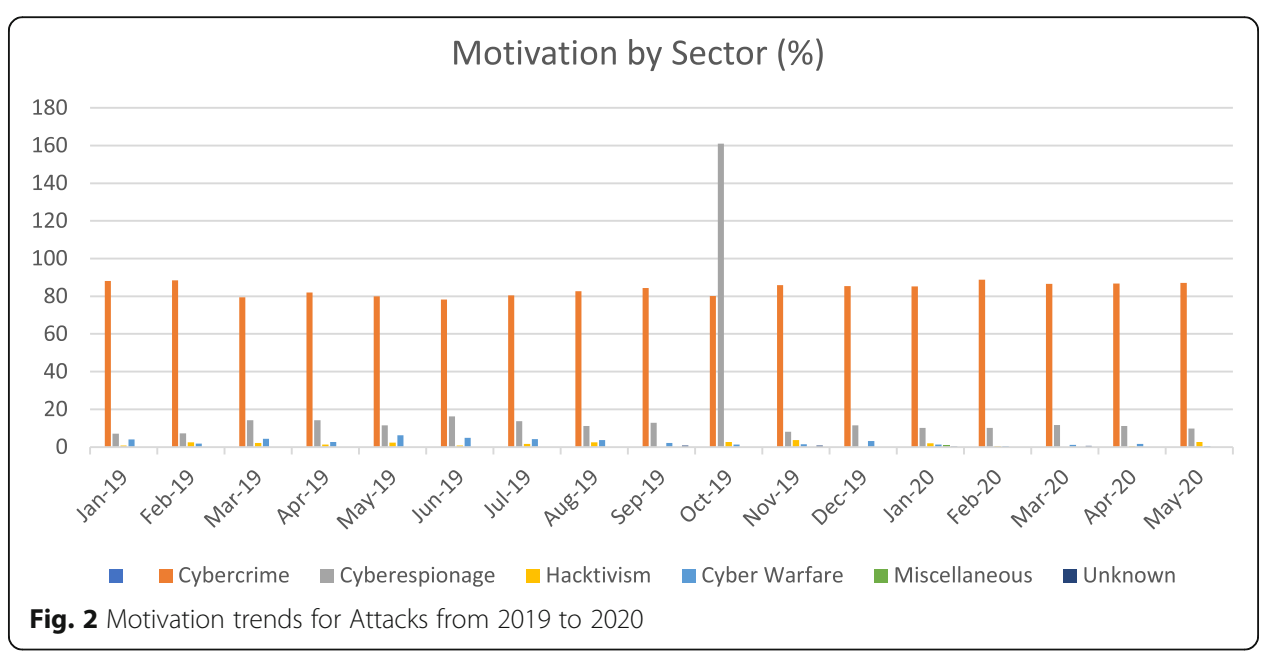




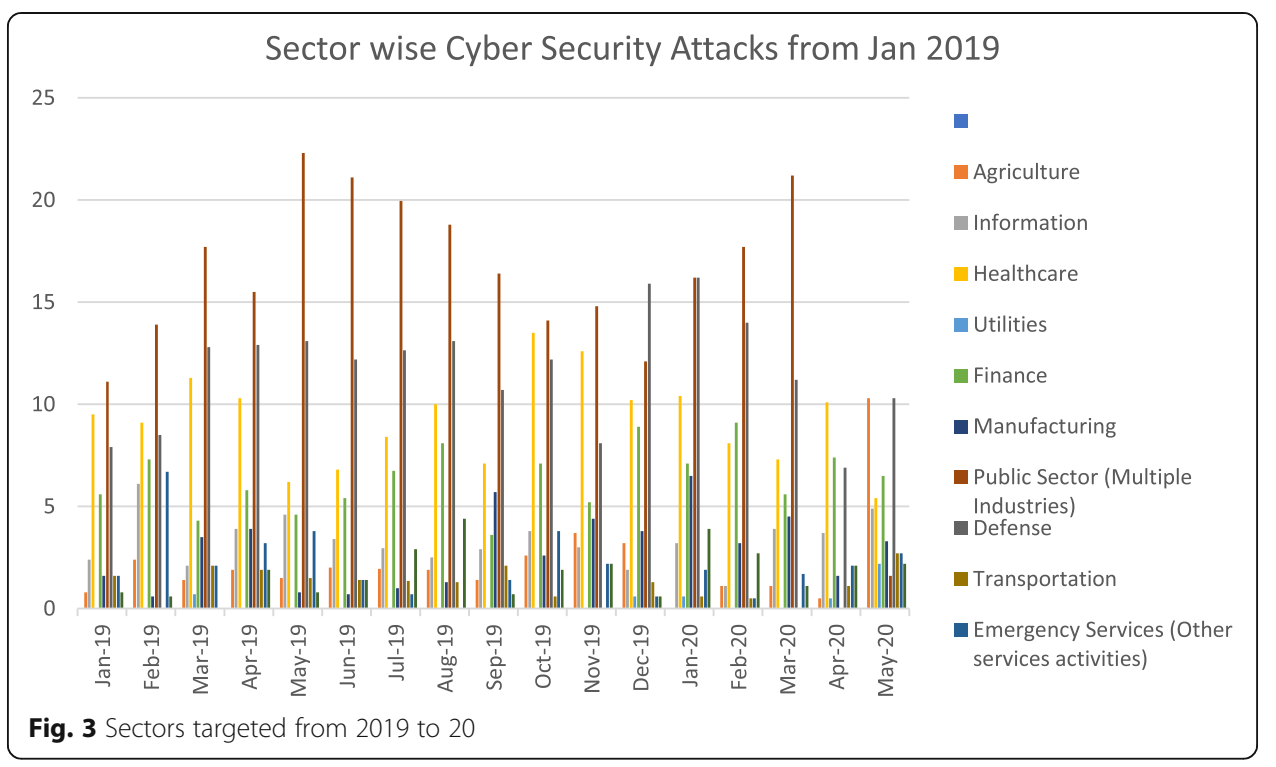

of how these I.T. systems function and vice versa applies to the I.T. personnel developing necessary patches etc. (Brook, 2018).

The complexity of the distributed generators also poses a considerable risk, unlike computers and other devices, which can be managed through upgrades and patches (Bekara, 2014). The different layers that encompass the virtual power plant are complex, and the interlinks in each layer interwinds with the other layers. The nature of architecture in VPP has many ICS devices interconnected, and the attacks can take place on any of the devices like AMI, SCADA, control and monitoring devices. Taking this into account, the entire network can be made unavailable with a single point of failure.

The number of critical infrastructures targeted across the countries is tabled in Table 2. Some notable special attacks between Jan-20 to June 2020 on the critical infrastructures is tabled in Table 3. As can be seen from the table, there is a rising volume and sophistication of the attacks on the infrastructure services and the need to safeguard the equipment, data becomes critical (Lathrop et al., 2016; Kimani et al., 2019).

Security breaches are a significant concern in virtual power plant systems and could lead to colossal property losses (Sha et al., 2016) in millions. Although the overall security apparatus in the virtual power plant is challenged due to many factors involved in the design; among them, the serious is the availability. Many security features are employed to protect and ensure availability, including some of the advanced access control mechanism (Alramadhan et al., 2017), signature-based authentication (Chen et al., 2018a, b, c), homomorphic encryption (Wang et al., 2013).

\section{Edge centric VPP architecture}

Security research on IoT-based platforms that intends to provide security solutions have been carried out by many researchers, and these efforts include Edge-based 


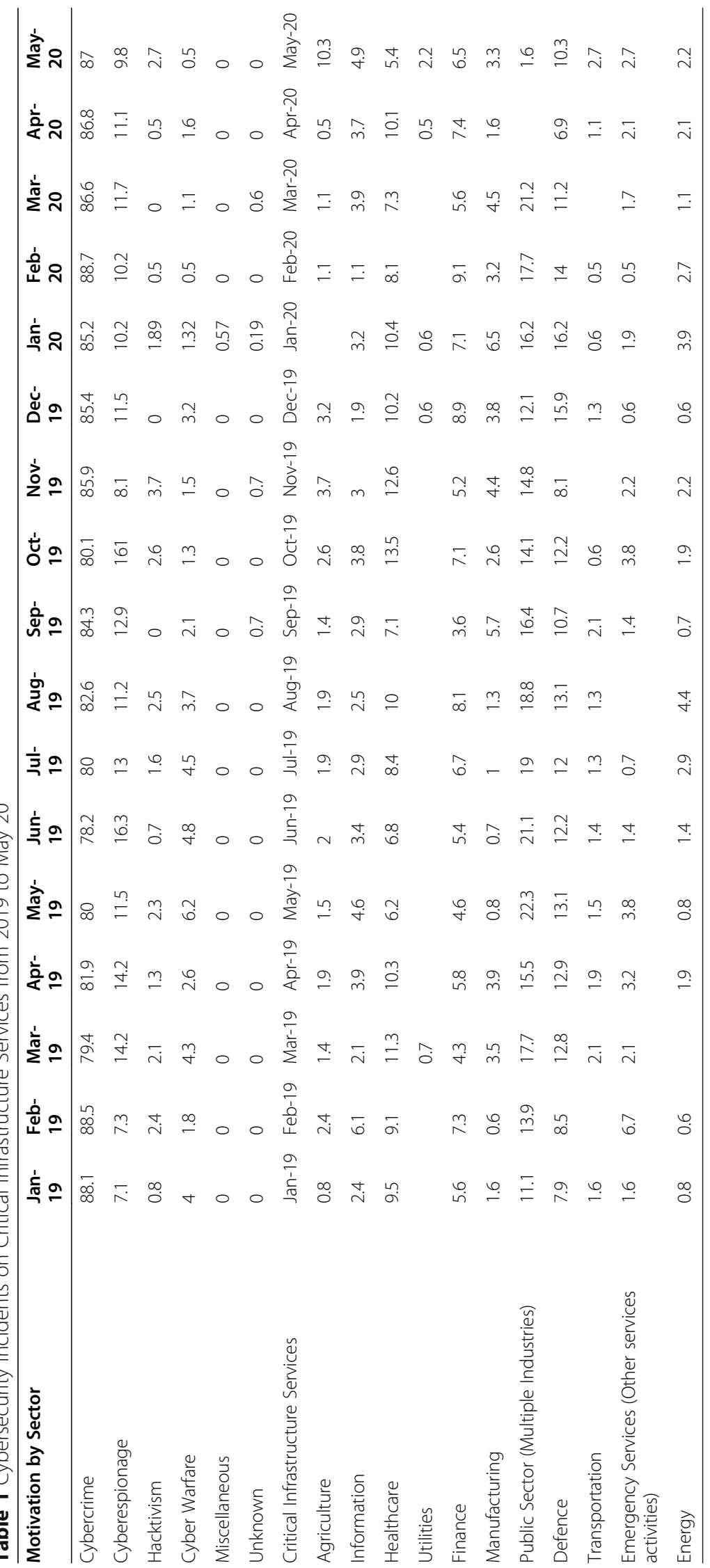


Table 2 Targeted Cybersecurity Attacks against Critical Services, Energy Sector etc.

\begin{tabular}{|c|c|c|c|c|c|}
\hline Year & Target Facility & Country & Agent & Impact & Ref \\
\hline 1982 & $\begin{array}{l}\text { Pipeline } \\
\text { explosion }\end{array}$ & Russia & Malware (SCADA) & Explosion and fire. & $\begin{array}{l}\text { (Zakhmatov et al., } \\
\text { 2011) }\end{array}$ \\
\hline 1992 & $\begin{array}{l}\text { Ignalina Nuclear } \\
\text { Power Station }\end{array}$ & Lithuania & $\begin{array}{l}\text { Virus (Control } \\
\text { System) }\end{array}$ & & (Panda, 2015) \\
\hline 1992 & $\begin{array}{l}\text { Chevron } \\
\text { (Warning System) }\end{array}$ & USA & Virus & $\begin{array}{l}\text { Hacking by a } \\
\text { disgruntled employee } \\
\text { who left thousands of } \\
\text { employees exposed } \\
\text { to toxicity }\end{array}$ & (Miller \& Rowe, 2012) \\
\hline 1994 & Salt River Project & USA & $\begin{array}{l}\text { Malware (Control } \\
\text { System) }\end{array}$ & $\begin{array}{l}\text { Hacking by an } \\
\text { employee, resulting in } \\
\text { deleting of critical files } \\
\text { resulting in } \\
\text { disconnecting water } \\
\text { supply to customers }\end{array}$ & (Panda, 2015) \\
\hline 1997 & Worcester Airport & USA & $\begin{array}{l}\text { Trojan (Control } \\
\text { System) }\end{array}$ & $\begin{array}{l}\text { Air traffic Control } \\
\text { tower system down } \\
\text { for six hours }\end{array}$ & (Panda, 2015) \\
\hline 1999 & Gazprom & Russia & Trojan (SCADA) & $\begin{array}{l}\text { No serious } \\
\text { consequences }\end{array}$ & (Panda, 2015) \\
\hline 2000 & $\begin{array}{l}\text { Maroochy Water } \\
\text { System }\end{array}$ & USA & Trojan & Water spillage & (Panda, 2015) \\
\hline 2001 & $\begin{array}{l}\text { Gas Processing } \\
\text { Plant }\end{array}$ & USA & Unknown & $\begin{array}{l}\text { Service outage in the } \\
\text { vicinity }\end{array}$ & (Panda, 2015) \\
\hline 2002 & PDVSA & Venezuela & Worm & Production outage & (Panda, 2015) \\
\hline \multirow[t]{2}{*}{2003} & $\begin{array}{l}\text { Banking Facility; } \\
\text { Ohio Nuclear } \\
\text { Facility }\end{array}$ & & $\begin{array}{l}\text { Slammer aka } \\
\text { Sapphire }\end{array}$ & Unknown & $\begin{array}{l}\text { (McGuinn, 2004; } \\
\text { Moore et al., 2003; } \\
\text { Poulsen, 2003) }\end{array}$ \\
\hline & Railways & & SoBig & $\begin{array}{l}23,000 \text { miles of one } \\
\text { railway line }\end{array}$ & (McGuinn, 2004) \\
\hline 2004 & $\begin{array}{l}\text { National Science } \\
\text { Foundation's } \\
\text { Amundsen-Scott } \\
\text { South Pole } \\
\text { Station }\end{array}$ & & Unknown & $\begin{array}{l}\text { Controlling life } \\
\text { support systems of } \\
\text { Antarctic research } \\
\text { station - Cyber Terror } \\
\text { Attack }\end{array}$ & (Poulsen, 2004) \\
\hline 2006 & L.A. Traffic Lights & USA & Malware & Reprogram the lights & (Panda, 2015) \\
\hline 2008 & Lodz Tram attack & Poland & & $\begin{array}{l}\text { Control of the tram } \\
\text { network }\end{array}$ & (Panda, 2015) \\
\hline 2008 & $\begin{array}{l}\text { Hatch Power } \\
\text { Plant }\end{array}$ & USA & Malware & $\begin{array}{l}\text { Unintentional shut } \\
\text { down due to an } \\
\text { update }\end{array}$ & (Desarnaud, 2017) \\
\hline 2009 & Civil Aviation & & Unknown & $\begin{array}{l}\text { Data compromise; } \\
\text { shutdown of systems }\end{array}$ & $\begin{array}{l}\text { (Gorman, 2009; Mills, } \\
\text { 2009) }\end{array}$ \\
\hline $\begin{array}{l}2009, \\
2010\end{array}$ & $\begin{array}{l}\text { Natanz - Iran's } \\
\text { Nuclear Plant } \\
\text { (Centrifuges) }\end{array}$ & $\begin{array}{l}\text { Iran and Many } \\
\text { countries }\end{array}$ & StuxNet & $\begin{array}{l}\text { Iran's Nuclear } \\
\text { centrifuges were } \\
\text { targeted. The } \\
\text { equipment was } \\
\text { replaced at an } \\
\text { alarming rate. }\end{array}$ & $\begin{array}{l}\text { (Naraine, 2010; } \\
\text { Falliere et al., 2011; } \\
\text { Nakashima \& Warrick, } \\
\text { 2012; Sanger, 2012; } \\
\text { Langner, 2013; } \\
\text { Kushner, 2013; } \\
\text { Thomson, 2013) }\end{array}$ \\
\hline 2011 & $\begin{array}{l}\text { No Specific } \\
\text { Target; } \\
\text { Iran Nuclear } \\
\text { Plants }\end{array}$ & $\begin{array}{l}\text { Iran and Many } \\
\text { countries }\end{array}$ & DuQu & Targeted; & $\begin{array}{l}\text { (Boldizsár et al., 2011; } \\
\text { Boldizs'ar et al., 2012; } \\
\text { (Guilherme \& Peter, } \\
\text { 2011; Kaspersky Corp, } \\
\text { 2011; Kaspersky Corp, } \\
\text { 2015) }\end{array}$ \\
\hline 2011 & Areva & France & Malware & Non-critical data theft & (Desarnaud, 2017) \\
\hline 2012, & Saudi Aramco & UAE, Italy & Shamoom (alias) & 30-35,000 Machines; & (Symantec Crop, \\
\hline
\end{tabular}


Table 2 Targeted Cybersecurity Attacks against Critical Services, Energy Sector etc. (Continued)

\begin{tabular}{|c|c|c|c|c|c|}
\hline Year & Target Facility & Country & Agent & Impact & Ref \\
\hline $\begin{array}{l}2015 ; \\
2016- \\
17 ; \\
2018- \\
19\end{array}$ & $\begin{array}{l}\text { (UAE); RasGas } \\
\text { (Qatar); Italy }\end{array}$ & & $\begin{array}{l}\text { Disttrack; } \\
\text { W32.Disttrack A; } \\
\text { W32.Disttrack B; }\end{array}$ & $\begin{array}{l}\text { D-Dos attack; FileWi- } \\
\text { per or File Eraser }\end{array}$ & $\begin{array}{l}\text { 2017; Leyden, J, 2012; } \\
\text { NewYork Times, 2012; } \\
\text { Perlroth, 2012; } \\
\text { Glymin, 2017; ENISA, } \\
2019 \text { Symantec Corp, } \\
\text { 2018, Trend Micro, } \\
\text { 2018) }\end{array}$ \\
\hline $\begin{array}{l}2012 \\
2015\end{array}$ & $\begin{array}{l}\text { Iran's Nuclear } \\
\text { Plant, Lebanon, } \\
\text { Sriya, Sudan, etc }\end{array}$ & & $\begin{array}{l}\text { Flame aka } \\
\text { Flamer, } \\
\text { (StuxNet. } \\
\text { Resource 207) }\end{array}$ & $\begin{array}{l}\text { Approx. } 1000 \\
\text { Machines, }\end{array}$ & $\begin{array}{l}\text { (Boldizsar et al., 2012; } \\
\text { sKyWiper Analysis } \\
\text { Team, 2012; } \\
\text { Alexander, 2012; } \\
\text { McElroy \& Williams, } \\
\text { 2012; Goodin, 2012; } \\
\text { Nakashima et al., } \\
\text { 2017), }\end{array}$ \\
\hline 2013 & $\begin{array}{l}\text { North American } \\
\text { Energy } \\
\text { Companies }\end{array}$ & & Dragonfly & $\begin{array}{l}\text { More than } 1000 \\
\text { energy companies in } \\
\text { North America and } \\
\text { Europe }\end{array}$ & $\begin{array}{l}\text { (BBC, 2014; Langill, } \\
\text { 2014; Symantec Corp, } \\
\text { 2014) }\end{array}$ \\
\hline 2014 & SCADA/ICS & & Havex & $\begin{array}{l}\text { Noticed in } 146 \\
\text { Command and } \\
\text { Control Server }\end{array}$ & $\begin{array}{l}\text { (David, 2014; Nelson, } \\
\text { 2016) }\end{array}$ \\
\hline 2014 & Korea Hydro & South Korea & Malware & $\begin{array}{l}\text { Reactor Manual theft; } \\
\text { electricity and } \\
\text { radiation exposure } \\
\text { data }\end{array}$ & (Desarnaud, 2017) \\
\hline \multirow[t]{2}{*}{2015} & $\begin{array}{l}\text { Ukrainian } \\
\text { Kyivoblenergo }\end{array}$ & & Black Energy 3 & $\begin{array}{l}225,000 \text { Customers } \\
\text { left without power for } \\
6 \mathrm{~h} \text { on a cold } \\
\text { December }\end{array}$ & (Lee, 2016) \\
\hline & Polish Airlines & & Unknown & $\begin{array}{l}1400 \text { passengers } \\
\text { grounded }\end{array}$ & (Rene, 2015) \\
\hline 2016 & $\begin{array}{l}\text { Gundremmingen } \\
\text { (German Nuclear } \\
\text { Power Plant) }\end{array}$ & & $\begin{array}{l}\text { W32.RAMNIT; } \\
\text { Conficker }\end{array}$ & $\begin{array}{l}\text { Isolated Incident on } \\
\text { the Power Plant as } \\
\text { the plant was isolated. } \\
\text { The previous version } \\
\text { of Conficker A, B, C, D, } \\
\text { E is reported to have } \\
\text { caused damage to } 1.7 \\
\text { million people. }\end{array}$ & $\begin{array}{l}\text { (Symantec Corp, } \\
\text { 2011) }\end{array}$ \\
\hline 2020 & $\begin{array}{l}\text { Public Health } \\
\text { Services }\end{array}$ & U.S.; & Ransomware & $\begin{array}{l}200,000 \text { email } \\
\text { addresses } \\
\text { compromised, leading } \\
\text { to many health } \\
\text { services being } \\
\text { impacted with } \\
\text { ransomware. Some } \\
\text { restored to paying the } \\
\text { ransom. }\end{array}$ & (Kochman, 2020) \\
\hline 2020 & & & AZORult; Trojan & $\begin{array}{l}\text { Spreads as payload } \\
\text { and often is used by } \\
\text { other payloads like } \\
\text { Djvu; primarily collects } \\
\text { user data }\end{array}$ & (Doffman, 2020) \\
\hline 2020 & $\begin{array}{l}\text { Citrix Application } \\
\text { Delivery } \\
\text { Controller }\end{array}$ & $\begin{array}{l}\text { Australia, } \\
\text { Canada, } \\
\text { Denmark, India, } \\
\text { Sweden, } \\
\text { Singapore U.K., } \\
\text { USA, }\end{array}$ & $\begin{array}{l}\text { FTP protocol } \\
\text { exploiting } \\
\text { vulnerability CVE- } \\
\text { 2019-1971; Algo- } \\
\text { rithm Command' } \\
\text { file/bin/Pwd }\end{array}$ & $\begin{array}{l}\text { World Wide Citrix } \\
\text { Gateway devices were } \\
\text { impacted affecting } \\
\text { banking, defence, } \\
\text { healthcare, energy, } \\
\text { technology, higher }\end{array}$ & (Glyer et al., 2020) \\
\hline 2020 & $\begin{array}{l}\text { Cisco Router } \\
\text { Exploitation Kit - }\end{array}$ & $\begin{array}{l}\text { Switzerland, } \\
\text { UAE- }\end{array}$ & $\begin{array}{l}\text { Remote code } \\
\text { execution; }\end{array}$ & & \\
\hline
\end{tabular}


Table 2 Targeted Cybersecurity Attacks against Critical Services, Energy Sector etc. (Continued)

\begin{tabular}{lllll}
\hline Year & Target Facility & Country & Agent & Impact \\
\hline & Cisco RV320 & Metasploit & \\
& & Module is & \\
& & exploiting vul. & \\
& CVE-2019-1653 & \\
& CVE-2019-1652 & \\
\hline
\end{tabular}

security solutions. (Mach et al., 2017; Errabelly et al., 2017; Montero et al., 2016; Hsu et al., 2018), firewall protection ( $\mathrm{Hu}$ et al., 2014), IDS (Roman et al., 2018; Haddadi et al., 2018), IPS, privacy preservation (Lu et al., 2017; Du, 2018; Singh et al., 2017), authentication protocols (Ali et al., 2018) etc. Edge-based protection in IoT centric devices mainly is concentrated on the user (Montero \& Serral-Gracia, 2016; Montero, 2015), device (Errabelly et al., 2017; Hsu et al., 2018) and endpoint security (Mukherjee et al., 2017).

The edge centric VPP architecture contains four major components, the cloud architecture, the edge layer, VPP operators, VPP end consumers/prosumers. Though resource-intensive, the cloud architecture is located far away from the virtual power plants consumers/ prosumers. Therefore the architecture cannot function efficiently, just as in IoT (Chen et al., 2016) due to its real-time application of distributing power on the grids. With the edge layer coming into effect, the components and the dynamics of the fundamental architecture changes with the Edge being the core as it can coordinate with different VPP's while at the same time complement and ensure optimised performance of the plant. The edge layer handles the VPP consumers queries or demand response in the edge environment, thus acting as a bridge between the users and the

Table 3 Critical Services impacted between Jan-Jun 2020

\begin{tabular}{|c|c|c|c|c|}
\hline $\begin{array}{l}\text { Month/ } \\
\text { Year }\end{array}$ & Target Facility & Country & Vector Type & Impact \\
\hline $\begin{array}{l}\text { Jan } \\
2020\end{array}$ & Picanol & $\begin{array}{l}\text { China, } \\
\text { Romania, } \\
\text { Belgium }\end{array}$ & Ransomware & No information \\
\hline $\begin{array}{l}\text { Jan } \\
2020\end{array}$ & Bapco Oil & Bahrain & Wiper Attack & No severe impact. \\
\hline $\begin{array}{l}\text { April } \\
2020\end{array}$ & $\begin{array}{l}\text { Water treatment } \\
\text { facilities }\end{array}$ & Isreal & Malware & SCADA devices \\
\hline $\begin{array}{l}\text { April } \\
2020\end{array}$ & $\begin{array}{l}\text { Government and } \\
\text { Industrial Organisations }\end{array}$ & Azerbaijan's & $\begin{array}{l}\text { COVID-19; RAT, } \\
\text { PoetRAT, Phishing }\end{array}$ & $\begin{array}{l}\text { Many devices and word } \\
\text { documents }\end{array}$ \\
\hline $\begin{array}{l}\text { April } \\
2020\end{array}$ & Energias de Portugal & Portugal & $\begin{array}{l}\text { Ragnar Locker } \\
\text { Malware } \\
\text { (Ransomware) }\end{array}$ & $\begin{array}{l}\text { 1 T.B. of sensitive data with a } \\
\text { demand for } 10.9 \text { million USD }\end{array}$ \\
\hline $\begin{array}{l}\text { April } \\
2020\end{array}$ & DESMI & Denmark & Ransomware & $\begin{array}{l}\text { Impacted a few communication } \\
\text { systems. }\end{array}$ \\
\hline $\begin{array}{l}\text { May } \\
2020\end{array}$ & Stadler & Switzerland & Ransomware & Data Theft \\
\hline $\begin{array}{l}\text { May } \\
2020\end{array}$ & Elexon & UK & Ransomware & $\begin{array}{l}\text { Internal Network - Electricity } \\
\text { Outage }\end{array}$ \\
\hline $\begin{array}{l}\text { May } \\
2020\end{array}$ & Bluescope & Australia & Ransomware & Manufacturing Operations \\
\hline $\begin{array}{l}\text { Jun } \\
2020\end{array}$ & Honda & $\begin{array}{l}\text { Japan / } \\
\text { Europe }\end{array}$ & Malware & \\
\hline
\end{tabular}


cloud (Sha et al., 2020). Researchers have made efforts to study and design appropriate security solutions for Edge. However, as the Edge is still in its infancy stage, security is still a long way to go (Sha et al., 2016). There needs to be continuous research for enhancing general cybersecurity (Venkatachary et al., 2018a).

Edge provides a new opportunity to explore new security mechanism for a virtual power plant. Most edge designs target offloading endpoint protection on the devices to edge. This could, in turn, pose new challenges in the form of resource constraints at the Virtual Power Plant layer.

\section{User-centric edge-based VPP security}

The key to cybersecurity is the weakest link, and the security is as good as the weakest link in the virtual power plant. With numerous VPP devices connected in a network, the prosumers/consumers access to generation, transmission \& distribution of energy and data using terminal devices is imminent. When considering the security aspects, significant concerns arise. For example, the consumer may either login in from a terminal device, which is trusted and secure or from an untrusted device. In the event of the prosumer logging from an untrusted device, the security could be compensated with additional security control measures as in the case of untrusted networks. The second aspect is that the consumer may not be aware of the security or have enough knowledge to manage the infrastructure, thereby resulting in potential risk effectively. Incorporating the Edge layer in managing such as scenario is an option; however, the drawbacks could be network challenges. The additional aspect could be on the personal security of the data on the network edge (Montero et al., 2016) and the virtual guard in Edge (Montero, 2015).

Figure 4 provides a brief overview of user-centric VPP security architecture. The design incorporates a trusted domain on the edge layer. The consumers/prosumers who generate, distribute and access data incorporate additional endpoint security. This translates to user security policy such as antivirus, firewalls (Basile et al., 2010), SCADA device isolations and other inspection tools. The edge layer, which is the trusted domain, will manage the secure access to the virtual power plant operator or the virtual power transmission system operator. The trusted domain, in this case, acts as an encapsulation layer to user-specific policy. The user is verified using RVA techniques to ensure trust between the prosumer. This design is based on the Network Functions Virtualisation technology to construct the edge layer. In this way, security can effectively be managed by deploying Edge.

\section{Device-centric edge security for VPP}

Unlike the user-centric security layer, the Device-Centric security layer is tailored to suit the prosumer or the consumer's requirement based on the resource availability, the data sensitivity and its impact on tasks and in consideration with the security needs of the endpoint VPP devices. Erabally et al. (Errabelly et al., 2017), in their paper, discuss the device-centric edge layer security comprising of six modules that function in a synchronised manner to handle specific security challenges in the IoT systems. The individual modules in each case include a systematic analysis of security profile, protocols, simulation, communication and request handling. 


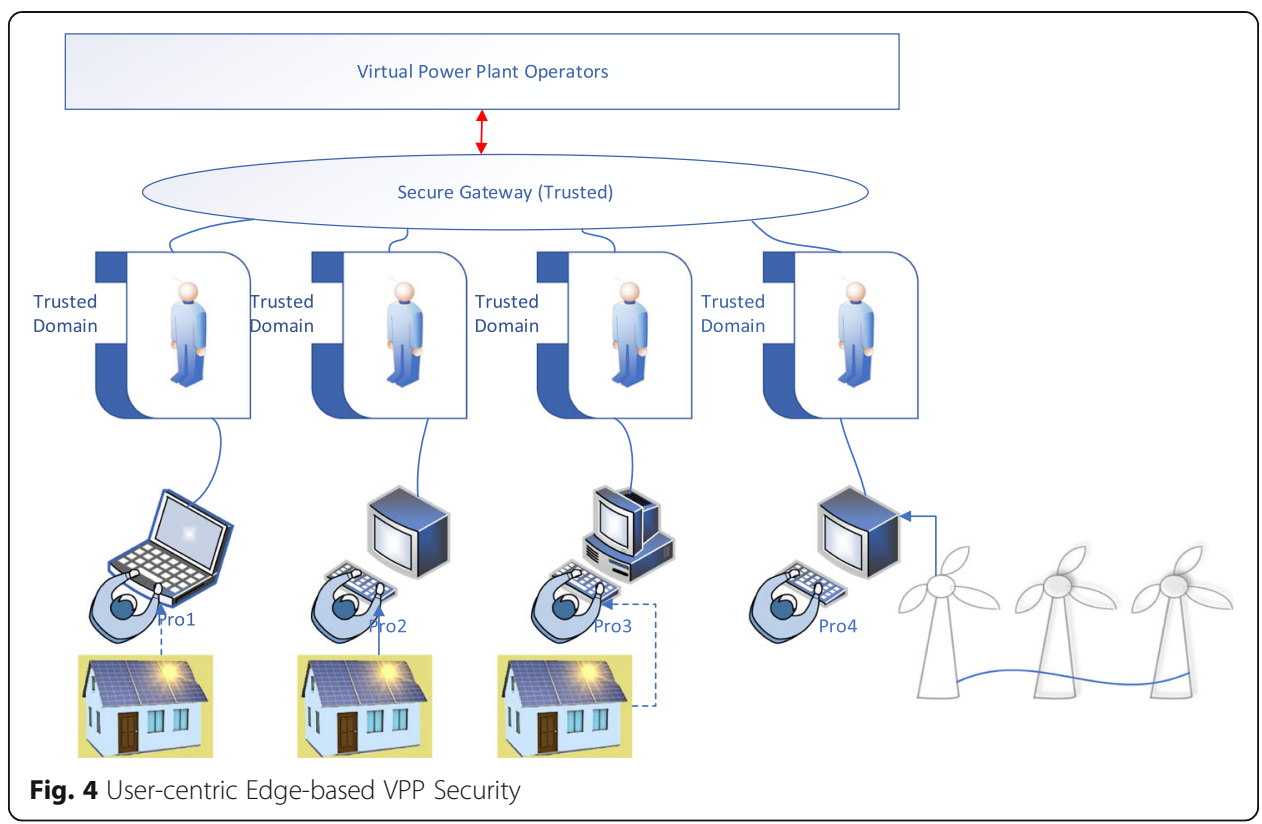

Figure 5 shows Device-Centric Edge security for Virtual Power Plant based on EdgeSec Model. In this model, each prosumer registers the devices with a specific security profile managing the module. The prosumer specific security details are then collected, and device-specific requirements are then identified. A detailed security check is implemented carrying out particular functions, one to verify the security dependency on the specific device registered and second to deploy the security function accordingly. The Edge then identifies a suitable protocol for each of the prosumer based on the resource availability and prosumer security profile. The security simulation model in the Edge simulates the instructions before deployment. This is done to protect the safety of the virtual plant prosumer's physical system. Other functions such as encrypting communication, coordination etc., work together.

\section{Firewall edge security for VPP}

Edge-based firewall systems is an innovative approach to protecting resources. $\mathrm{Hu}$ et al. base their research using software-defined networking and suggest a comprehensive framework to detect anomalies and offer effective firewall policy resolutions accurately. This SDN based firewall has three functional components, violation detection, flow tracking and authorisation. Violation detection is handled using traditional firewall packet filtering techniques. Flow tracking is based on headers using a Header Space Analysis (HAS) tool, one of the several invariant verification tools. (Kazemian et 1., 2012; Kazemian et al., 2013; Khurshid et al., 2013). The authors further define Firewall Authorisation Space to allow or deny packets based on the firewall rules, thereby enabling conversion into smaller denied and allowed spaces. On the other hand, the distributed firewall architecture is placed at the network edge and adopts a master-slave architecture, thereby providing centralised management (Markham et al., 2001). 


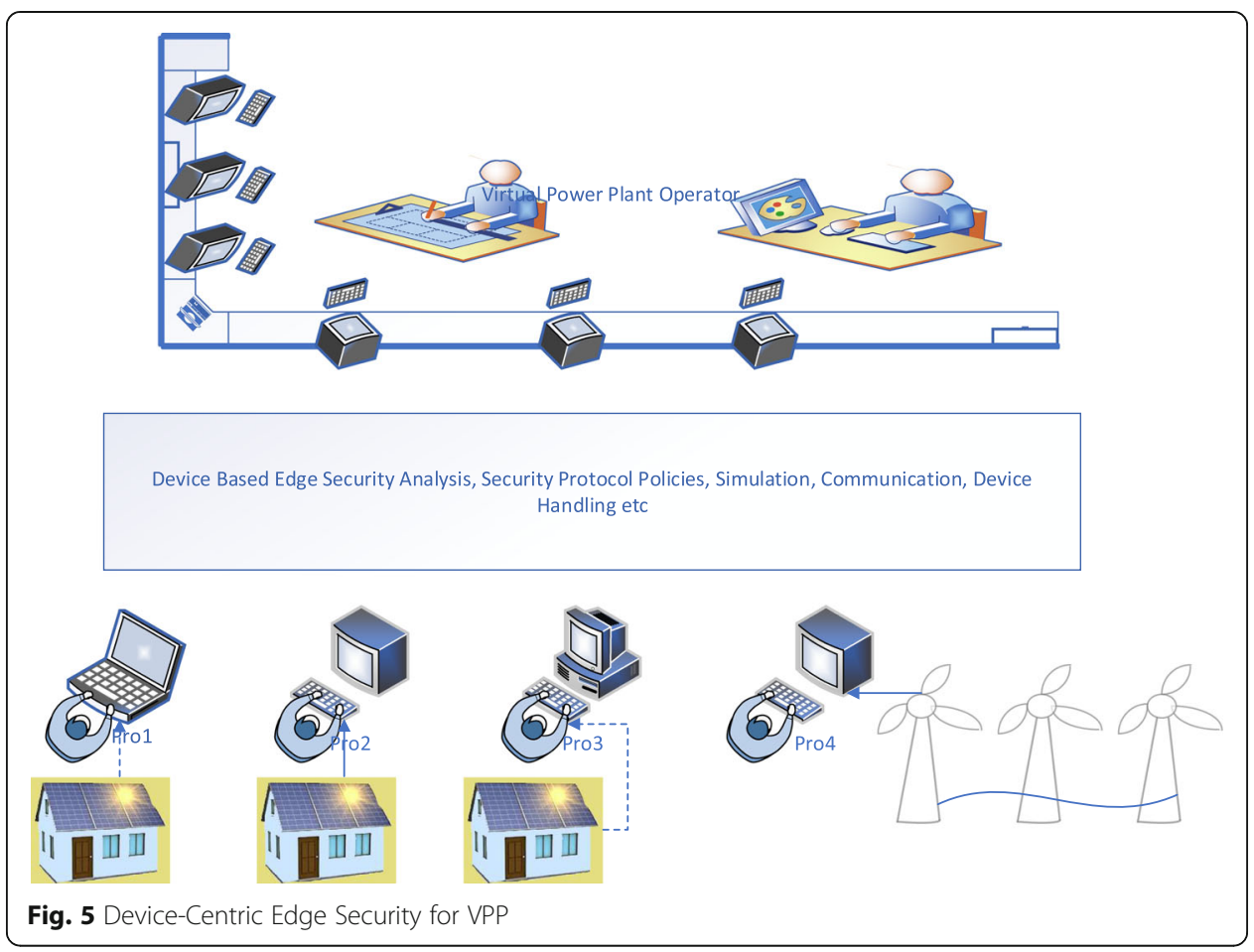

Most prosumers in a virtual power plant are small-time operators and cannot support huge firewalls or necessary infrastructure to support them. Assuming that a single virtual power plant operator has a considerable number of generators connected, it will be too costly to manage the installation of firewalls.

Figure 6 describes an edge-based firewall design. The firewall policies are converted into flow policies. The conflictions in these policies are resolved and later applied as a firewall rule. These firewall rules are applied in the edge layer. The incoming and the outgoing traffic out of the individual prosumers/consumers are examined and later allowed or disallowed. The edge-based firewalls are feasible and easier to deploy. The managing of the firewall is also easy as there is only one centralised firewall. Further, the system can be modified to suit the need-base security model.

\section{Edge-based intrusion detection systems (EIDS)}

According to security researchers, the energy sector is the most frequently targeted sector by cybercriminals. As of 2019, 16\% of the attacks were concentrated on energy with advance attacks and remained at the top 10 targeted industries (Kreyenber, 2019). The recent DDoS attacks in 2016 caused significant losses (Brewster, 2016). The availability of a distributed intrusion detection could significantly have enabled the security researchers to detect these type of security attacks at an early stage and prevent it (Sha et al., 2020). The availability of the information in this makes a vital difference. Researchers. The use of A.I. and machine learning algorithms in the security layer could significantly change the dynamics of security due to learning from multiple sources. 


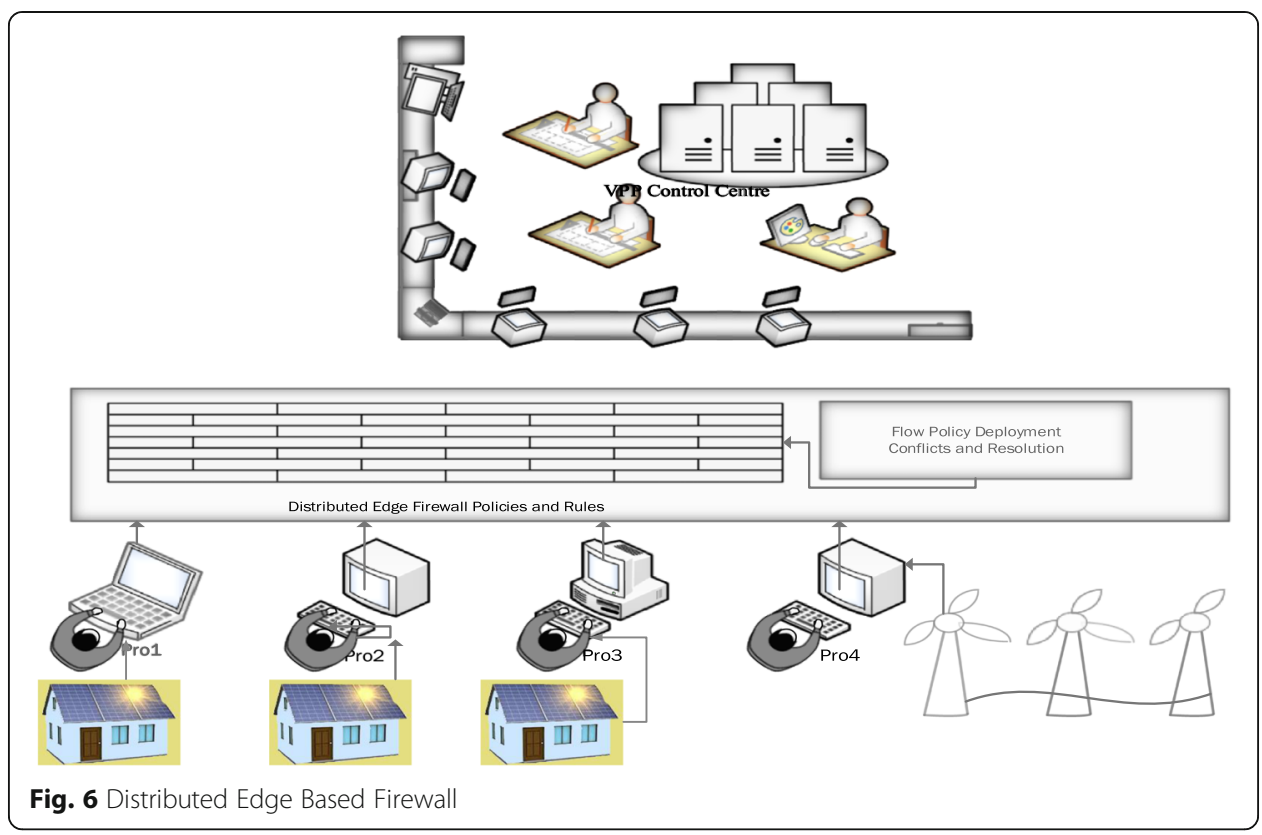

The ease of adaptability to the changing scenarios could make a huge difference. Some notable research in apply edge-based IDS is discussed in papers by several researchers Yaseen et al. (Yaseen et al., 2016). (Roman et al., 2018). (Haddadi et al., 2018). (Roman et al., 2018) suggest a VIS (Virtual Immune System) to analyse network traffic with two functions: the kernel and the immune cells. The orchestrator inside the kernel is used for the configuration and deployment of the immune cells. The immune cells scan, analyse, manages the traffics and is also responsible for storing logs. Haddadi et al., in their research paper on SIOTOME, illustrate Edge-based architecture for IoT security. Here, the edge data collector is used for monitoring the network traffic information in the IoT devices. The edge layer analyses the traffic collected information on network threats, attacks, and feedback on the controller's collected information. The SIOTOME also enables the defence mechanism like network isolation (Nunes et al. 2014), limiting the attack surface area. They also aid in stopping vulnerability scans and DDoS attacks.

Figure 7 and Fig. 8 shows a simple Edge-based IDS system design and Virtual Immune System. The DTM (Distributed Traffic Monitoring System) collects the information from the individual prosumers in real-time. The system then runs the intrusion detection algorithms. There is a collaborative compilation of the traffic, and the results are then enforced on to the network controller.

\section{Edge-based authentication and authorisation in virtual power plants}

Industrial Control system attacks in the energy sector have witnessed a surge in recent times (Wilhoit et al., 2013; Dasgupta et al., 2017). This brings into focus two main features, authentication and authorisation, which can unauthorised attacks and DDoS attacks (Kolias et al., 2017). The drawback in the devices using end to end communication is difficult to create due to heteromerous peers. Secondly, signature-based 


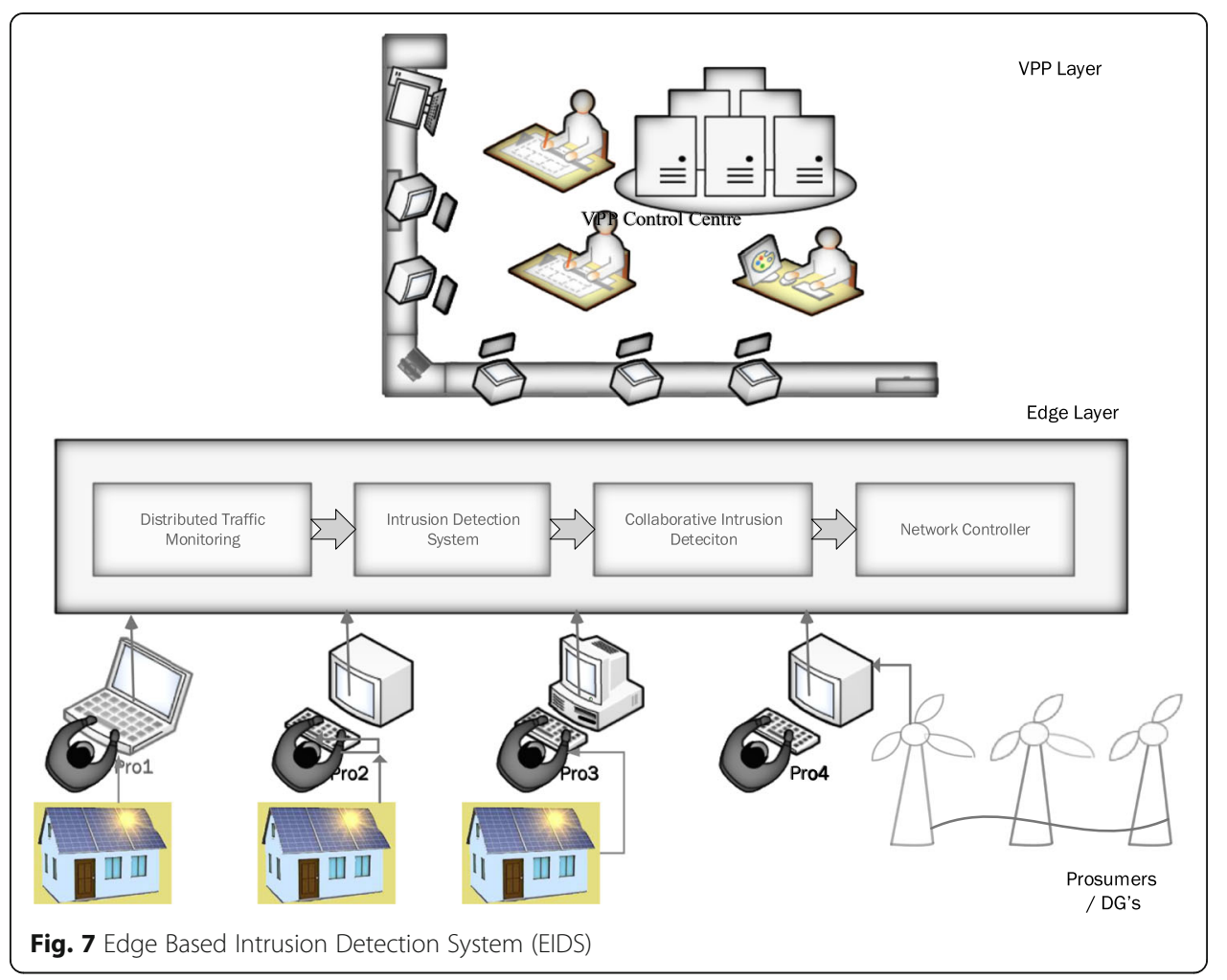

algorithms can only be employed in the traditional authentication mechanism, making it difficult to apply in virtual power plant areas. The insertion of an Edge layer improves the prospects of utilising multi-authentical protocols and multiple phase authorisation. Sha et al., in their paper, discuss the Edge-based device as a mutual authenticator with a two-phase authentication protocol. In the first stage, the edge authenticator authenticates using a digital signature and gathers users credentials. The credentials obtained are then reauthenticated using a mutual authenticator using a symmetric key-based algorithm (Sha et al., 2014; Sha et al., 2017). Researchers have also attempted to enhance the authentication protocols using RFID based algorithms. (Fan et al., 2012; Gope et al., 2018).

The process of authenticating prosumers in a virtual power plant is segmented, including the prosumers end devices and the edge layer. Depending on the characteristics of the communication, the protocols can be customised. Thus, the Edge layer works as the man in the middle, which helps set up mutual authentication and authorisation. As the Edge provides multiple authentication interfaces; thus, it provides a secure interface (Dasgupta et al., 2017).

\section{Edge-based privacy-preserving designs}

Virtual power plants are a host of data hubs as prosumers and consumers contribute to power generation and attract vast cybercriminals. Data privacy takes precedence and requires stringent policies, monitoring and protection. As more and more devices get connected to virtual power plant operators, the data available to the plant operators is 


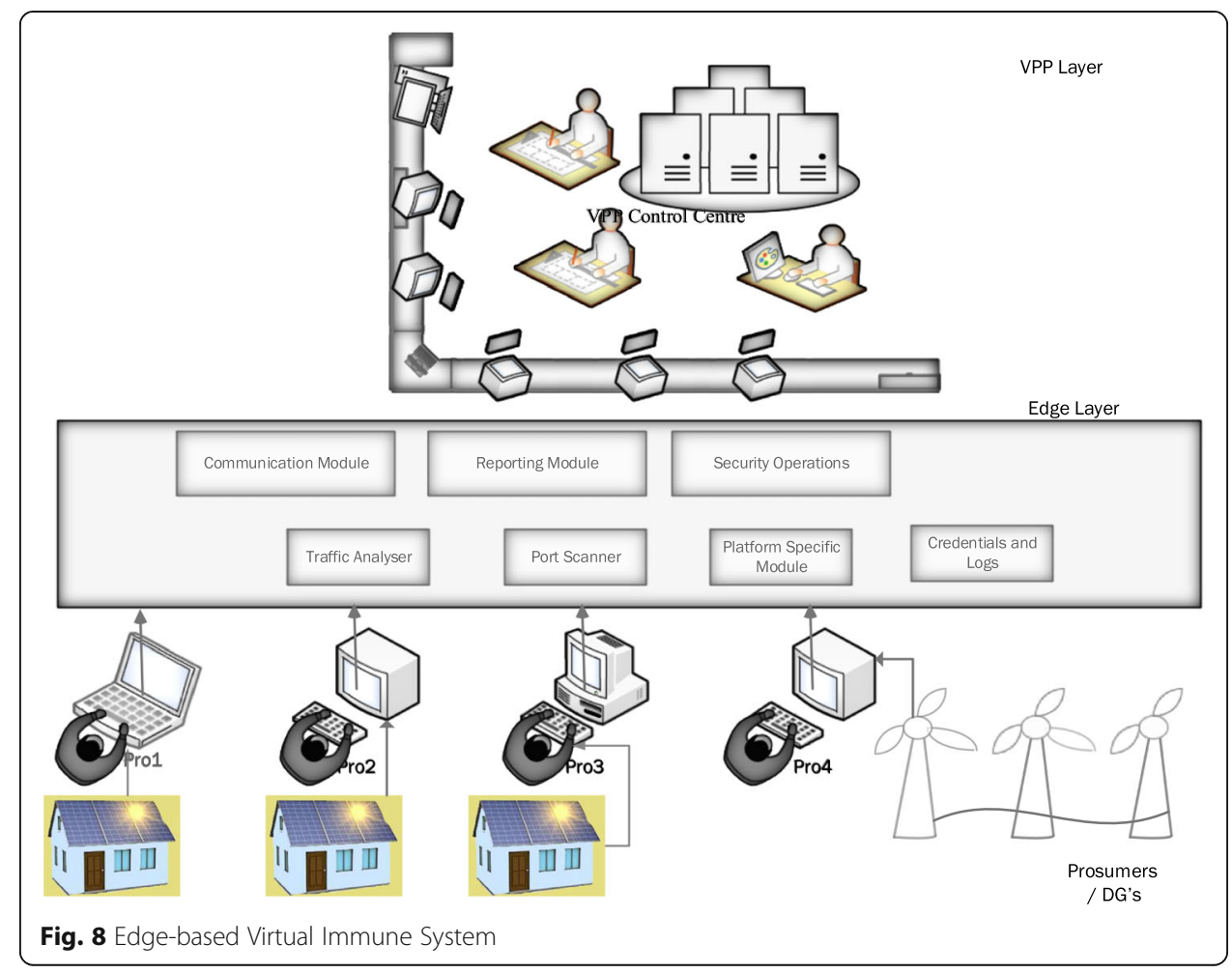

vast and needs to be protected from both the prosumer and operator levels. It is possible to achieve greater privacy by adapting different privacy protection algorithms like differential privacy (Dwork, 2014), k-anonymity (Sweeney, 2002; Sha et al., 2006; Xi et al., 2007), privacy preservation aggregation (Lu et al., 2017) etc.

$\mathrm{Lu}$ et al., in their paper on privacy protection, suggest a method to keep the privacy intact by using a lightweight privacy-preserving data aggregation scheme for IoT devices. They use a message authentication code to process the information reported by the devices. Once the Edge receives the authenticate of the devices by comparing the MAC and then generate a value for the IoT applications. Gentry, in his thesis, for solving a cryptographic problem, present fully homomorphic encryption. They use a simple algorithm based on a bootstrap mechanism for encryption through a recursive selfembedding algorithm "Paillier" (Gentry, C, 2009). One way hashing technique and the Chinese remainder theorem have also been used to address the privacy problem (Pei et al., 1996; McSherry \& Talwar, 2007).

Figure 9 shows a brief overview of applying Edge design for preserving privacy. The Edge architecture uses privacy-preserving aggregation, k-anonymity and differential privacy together to decipher the queried data and responses between the prosumers and virtual plant operators to ensure data protection at either end. Data transmitted is verified, authenticated and established, thus ensuring privacy protection.

\section{Discussion}

The previous section portrays different research techniques that have been applied in different platforms and suggest applications in virtual power plant areas. The Edge 


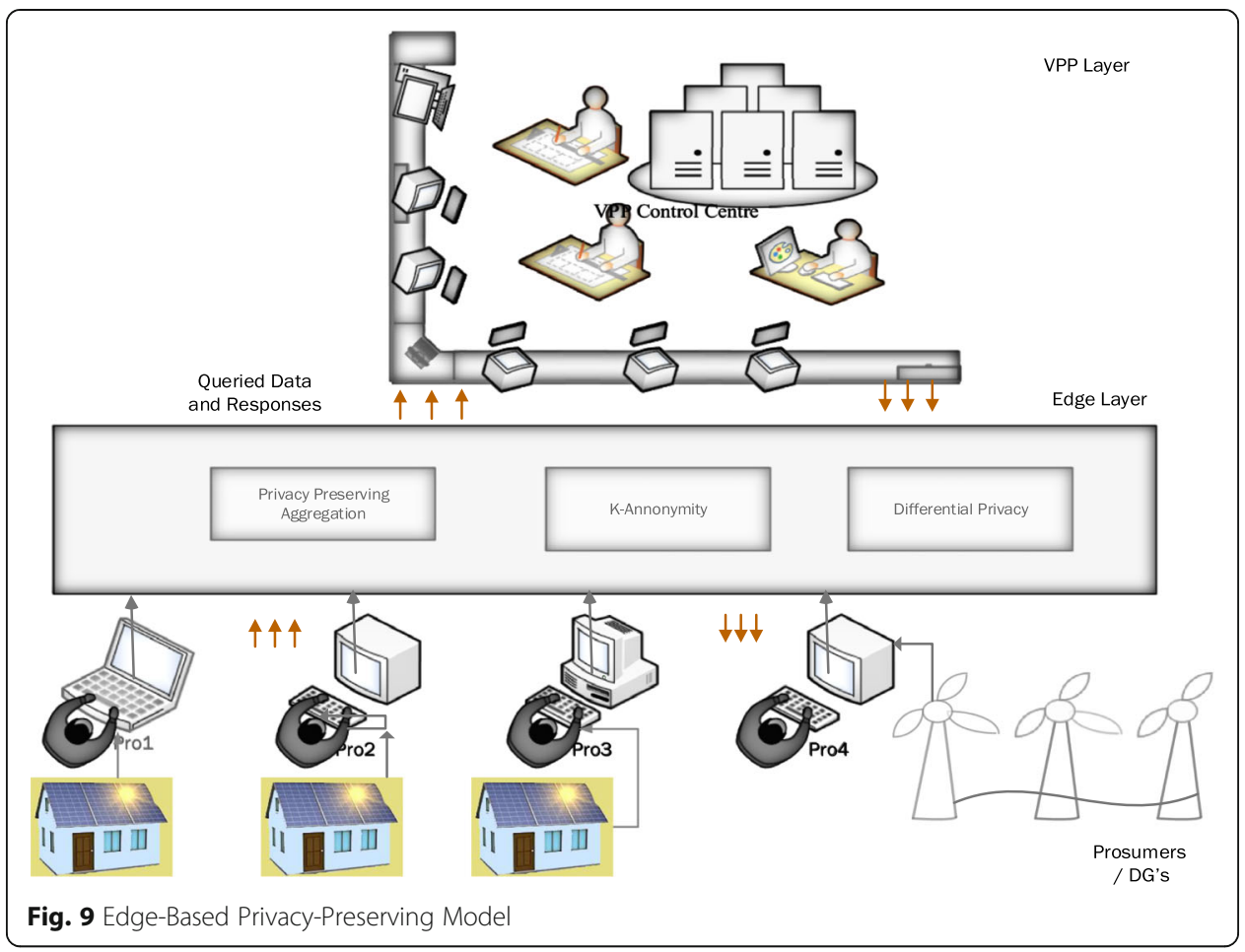

computing methods are still in their infancy, and there are still numerous challenging issues that need to be addressed. Though the Edge layer provides a new model for providing security solution, the Edge has a vast surface area and could, in turn, be subjected to attack. Addressing the security concerns in the Edge layer is not a huge task as opposed to other data centre securities. Thus, warranting more research in the area.

Though there are several Edge-based privacy protection techniques, the Edge protocols applied may, in turn, start to track the data and may have vested interests. (Razeghi \& Voloshynovski, 2018) (Sharma \& Chen, 2017). This in-turn, will warrant other innovative security solutions for protecting privacy. Studies have been carried out using Isolation techniques, but it remains to be seen how to implement the techniques in the edge layer effectively. It also remains to be seen how to effectively adopt new algorithms to establish trusted security between the Edge devices and the prosumer devices. Researchers have also proposed adopting machine learning algorithms to advance researches in intrusion detection techniques. Buczak et al. present a survey on using data mining and machine learning techniques as methods for intrusion detection. (Buczak \& Guven, 2016). The popularity of deep learning has also contributed to understanding intrusion detection (Yin et al., 2017). However, the machine learning algorithmic methods require huge data sets and are most central to the environment and hence is a drawback for deployment in small Edge environments. Secondly, machine learning algorithms are more suited and beneficial in the cloud. This provides us with an opportunity to research and deploy cross-domain algorithms for intrusion detection.

Machine learning algorithms are learners, and they learn from the different attack detection techniques employed for intrusion detection. Therefore, the returned data has to be accurate and correct, on which decisions are based (Sha \& Zeadally, 2015). However, there is a lack of data protocols to analyse and ensure the correctness of a high- 
quality dataset. In this environment, cross-domain verifications would be of great interests. (Sha et al., 2010). There has been a little contribution towards researching the cost impacts in the Edge environment. Research in the cost-benefit analysis of deploying Edge should be encouraged with active participation and collaboration. Though the safety of the prosumer equipment is extremely important, the research in this field is limited to a few. As virtual power plants are real-time, the requirements are real-time, thus complicating the simulations and modelling a suitable design (Weber \& Studer, 2016). This also poses a challenge for response time to potential safety risks to minimise damages caused towards the equipment etc.

Virtual machines have found widespread use in many areas, and it is being researched in the application of the Edge layer. The ease of deploying V.M.s in the environment also pose a security threat as more than one V.M. could be deployed in the layer (Tsai, 2012; Eldefrawy et al., 2017). Considering the virtual power plant environment, these machines need to be simple, light and should meet the requirements of the prosumers. Thus, there is a huge scope for researching in this area.

\title{
Remarks and conclusions
}

The challenge of securing virtual power plants systems has generated great interests among researchers. The nature and operations of the virtual plants and prosumer/consumer generators pose significant challenge and risks. The advancement of new technologies in computing like edge computing has resulted in researching edge-based security systems for virtual power plants and distributed generators. This paper aims to present an assessment and a way of adopting Edge-based security systems in virtual power plants. In this context, it has defined to provide Edge-centric architecture. These solutions aim to address key protection of VPP devices, including a comprehensive cybersecurity architecture, application of Edge-based firewalls, intrusion detection systems, Edge-based authentication and authorisations.

\footnotetext{
Abbreviations

IoE: Internet of Energy; DDoS: Distributed Denial of Service; RTU: Remote Terminal unit; MTU: Master Terminal Unit; SCADA: Supervisory Control and Data Acquisition; TSO: Transmission System Operator; DSO: Distribution System Operator; AMI: Advanced Metering Infrastructure; A.I: Artificial Intelligence
}

Authors' contributions

The author(s) read and approved the final manuscript.

\section{Declarations}

Competing interests

The authors declare that they have no competing interests.

\author{
Author details \\ ${ }^{1}$ Grant Thornton, Plot 50370, Acumen Park, Fairgrounds, Gaborone, Botswana. ${ }^{2}$ Department of Network and \\ Infrastructure Management, Faculty of Engineering and Technology, Botho University, Gaborone, Botswana. \\ ${ }^{3}$ Department of Information Technology, Faculty of Engineering and Technology, Botho University, Gaborone, \\ Botswana \\ Received: 1 December 2020 Accepted: 11 March 2021 \\ Published online: 31 March 2021 \\ References \\ Alexander, G. (2012). The Flame: Questions and Answers. Kaspersky Labs, Kaspersky Labs. Retrieved 07 06, 2017, from https:// \\ securelist.com/34344/the-flame-questions-and-answers-51/ \\ Ali Z, Hossain MS, Muhammad G, Ullah I, Abachi H, Alamri A (2018) Edge-centric multimodal authentication system using \\ encrypted biometric templates. Futur Gener Comput Syst 85:76-87. https://doi.org/10.1016/j.future.2018.02.040
}


Alramadhan, M., K. Sha, (2017). An overview of access control mechanisms for the internet of things. 26th International Conference on Computer Communications and Networks (ICCCN) (pp. 1-7). Vancouver, Canada: IEEE doi:https://doi.org/1 $0.1109 /$ ICCCN.2017.8038503

Basile C, Lioy A, Scozzi S, Vallini M (2010) Ontology-based security policy translation. J Information Assurance Security 5(1): $437-445$

BBC. (2014). Energy firms hacked by 'cyber-espionage group Dragonfly. BBC News (Online), BBC. BBC. Retrieved 06 09, 2017, from http://www.bbc.com/news/technology-28106478

Bekara, C. (2014). Security issues and challenges for loT based smart grid. International Workshop on communicating objects and machine to machine for mission-critical applications (COMMCA). Doi:https://doi.org/10.1016/j.procs.2014.07.064

Boldizsar B, Gabor, P'., Levente, B., Mark, F. (2012) The cousins of Stuxnet: Duqu, flame, and gauss. Future internet, MDPI 4(4): 971-1003. https://doi.org/10.3390/fi4040971

Boldizsár, B., Gábor, P., Levente, B., Félegyházi, M. (2011). Duqu: A Stuxnet-like malware found in the wild. Budapest University of Technology and Economics, Department of Telecommunications. Budapest, Hungary: Laboratory of Cryptography and System Security (CrySyS). Retrieved 06 11, 2017, from https://www.crysys.hu/publications/files/bencsathPBF11duqu.pdf

Brewster, T. (2016). How hacked cameras are helping launch the biggest attacks on the Internet has ever seen. Retrieved from www.forebes.com/sites: https://www.forbes.com/sites/thomasbrewster/2016/09/25/briankrebs-overwatch-ovh-smashedbylargest-ddos-attacks-ever/\$705007235899

Brook, C. (2018, 12, 05). Data Protection 101: What is ICS Security. Retrieved from www.digitalguardian.com: https://digitalgua rdian.com/blog/what-ics-security

Buczak AL, Guven E (2016) A survey of data mining and machine learning methods for cybersecurity intrusion detection. IEEE Communications Surveys \& Tutorials 18(2):1153-1176. https://doi.org/10.1109/COMST.2015.2494502

Cai Z, He Z (2019) Trading private range counting over big loT data. In: IEEE 39th International Conference on Distributed Computing Systems. IEEE, Texas, pp 144-153

Cai Z, Zheng X (2019) A private and efficient mechanism for data uploading in smart cyber-physical systems. IEEE Transactions on Network Science and Engineering 7(2):766-775. https://doi.org/10.1109/TNSE.2018.2830307

Cai Z, Zheng X, Yu J (2019) A differential-private framework for urban traffic flows estimation via taxi companies. IEEE Transactions on Industrial Informatics 15(12):6492-6499. https://doi.org/10.1109/TII.2019.2911697

Chen M, Hao Y, Gharavi H, Leung V (2019) Cognitive information measurements: a new perspective. Inf Sci 505:487-497. https://doi.org/10.1016/j.ins.2019.07.046

Chen M, Hao Y, Lai C, Wu D, Li Y, Hwang K (2018a) Opportunistic task scheduling over co-located clouds in the mobile environment. IEEE Transaction on Services Computing 11(3):549-561. https://doi.org/10.1109/TSC.2016.2589247

Chen M, Zhou J, Tao G, Yang J, Hu L (2018b) Wearable effective robot. IEEE Access 6:64766-64776. https://doi.org/10.1109/A CCESS.2018.2877919

Chen S, Zeng P, Choo KR, Dong X (2018c) Efficient ring signature and group signature schemes based on Q-ary identification protocols. Comput J 61(4):545-560. https://doi.org/10.1093/comjnl/bxx112

Chen X, Jiao L, Li W, Fu X (2016) Efficient multi-user computation offloading for mobile-edge cloud computing. IEEE/ACM Trans Networking 5(1):2795-2808

Dasgupta D, Roy A, Nag A (2017) Multi-factor authentication. Advances in User Authentication, pp 185-233. https://doi.org/1 0.1007/978-3-319-58808-7_5

David. (2014). Havex Hunts For ICS/SCADA Systems. (F-Secure Labs) Retrieved 06 15, 2017, from https://www.f-secure.com/ weblog/archives/00002718.html

Desarnaud G (2017) Cyber attacks and energy infrastructures - anticipating risks. IFRI Centre for Energy, Paris

Doffman, Z. (2020). Warning: You must not download this dangerous Coronavirus map. Retrieved from www.forbes.com: https:/www. forbes.com/sites/zakdoffman/2020/03/11/warning-you-must-not-download-this-dangerous-coronavirus-map/\#4049aef83253

Du M (2018) Big data privacy-preserving in multi-access edge computing for heterogeneous internet of things. IEEE Communication Magazine 56(8):62-67. https://doi.org/10.1109/MCOM.2018.1701148

Dwork C, Roth A (2014) The algorithmic foundations of differential privacy. Foundations and Trends in Theoretical Computer Science, pp 211-407

Eldefrawy, K., Rattanavipanon, N., Tsudik, G. (2017). Fusing hybrid remote attestation with a formally verified microkernel: lessons learned. 2017 47th Annual IEEE/IFIP International Conference on Dependable Systems and Networks Workshop (DSN-W) (pp. 141-144). Denver, USA: IEEE. doi:https://doi.org/10.1109/DSN-W.2017.31

ENISA. (2019, 01 07). Shamoon Campaigns with Disttrack. (European Union) retrieved 08 04, 2019, from European Union Agency for cyber security: https://www.enisa.europa.eu/publications/info-notes/shamoon-campaigns-with-disttrack

Errabelly, R., Sha, K., Wei, W., Yang, T.A., Wang, Z. (2017). Edges: design of an edge layer security service to enhance internet of things security. First IEEE International Conference on Fog and Edge Computing (ICFEC 2017). IEEE

Falliere, N., Liam O.M., Chien, E. (2011). Symantec Response - W32.Stuxnet Dossier. Symantec Labs, Symantec. Symantec. Retrieved from https://www.symantec.com/content/en/us/enterprise/media/security_response/whitepapers/w32_stuxnet_dossier.pdf

Fan, K., Li, J., Li, H., Liang, X., Shen, X., Yang, Y. (2012). ESLRAS: a lightweight RFID authentication scheme with high efficiency and strong security for IoT. 2012 4th International Conference on Intelligent Networking and Collaborative Systems (INCoS) (pp. 323-328). Bucharest: IEEE. doi:https://doi.org/10.1109/iNCoS.2012.48

Gentry, C. (2009). A fully Homomorphic encryption scheme. (Thesis), 1-209. Stanford University

Glyer, C., Perez, D., Jones, S., Miller, S. (2020). This Is Not a Test: APT41 Initiates Global Intrusion Campaign Using Multiple Exploits Retrieved from www.fireeye.com: https://www.fireeye.com/blog/threat-research/2020/03/apt41-initiates-globalintrusion-campaign-using-multiple-exploits.html

Glymin, E. (2017). Detailed Threat Analysis of Shamoon 2.0 Malware. Retrieved 08 04, 2019, from global secure solutions: https://globalsecuresolutions.com/detailed-threat-analysis-of-shamoon-2-0-malware/

Goodin, D. (2012). Discovery of new "zero-day" exploit links developers of Stuxnet, Flame. (arstechnica) retrieved 06 12, 2017, from https://arstechnica.com/security/2012/06/zero-day-exploit-links-stuxnet-flame/

Gope P, Amin R, Islam H, Kumar N, Bhalla VK (2018) Lightweight and privacy-preserving RFID authentication scheme for distributed loT infrastructure with secure localisation services for the smart city environment. Futur Gener Comput Syst 83:629-637. https://doi.org/10.1016/j.future.2017.06.023 
Gorman, S. (2009). FAA's Air-Traffic Networks Breached by Hackers. (the wall street journal) retrieved 06 12, 2017, from http:// online.wsi.com/articles/SB124165272826193727

Guilherme, V., Peter, S. (2011). The Day of the Golden Jackal - The Next Tale in the Stuxnet Files: Duqu. McAfee. McAfee. Retrieved 06 09, 2017

Haddadi, H., Christophides, V., Teixeira, R., Cho, K., Suzuki, S., Perrig, A. (2018). Siotome: an edge-isp collaborative architecture for loT security. 1st International Workshop on Security and Privacy for the Internet-of-Things (IoTSec), (pp. 42-45). Florida, USA

Hsu R, Lee J, Quek T, Chen J (2018) Reconfigurable security: edge computing based framework for loT. IEEE Netw 30(5):92-99

Hu, H., Han, W., Ahn, G., Zhao, Z. (2014). Flow guard: building robust firewalls for software-defined networks. 3rd Workshop on hot topics in software-defined networking. ACM

Huang, C., Wu, Z., Lin, S. (2019). The mobile edge computing (MEC)-based VANET data offloading using the staying-timeoriented k-hop away offloading agent. 2019 International Conference on Information Networking (pp. 357-362). Kuala Lumpur, Malaysia: IEEE

Jaber M, Imran MA, Tafazolli R, Tukmanov A (2016) 5 G backhaul challenges and emerging research directions: a survey. IEEE Access 4:1743-1766. https://doi.org/10.1109/ACCESS.2016.2556011

Kaspersky Corp. (2011). Duqu: Steal Everything. (Kaspersky Labs) retrieved 05 09, 2017, from http://www.kaspersky.com/about/ press/major_malware_outbreaks/duqu

Kaspersky Corp. (2015). The DuQu 2.0 Technical Details- The Mystery of DuQu 2.0 - Sophisticated Cyber Espionage Actor. Kaspersky Labs, research Labs. Kaspersky Labs

Kaspersky Labs. (2020, 07). Kaspersky ICS-CERT. (Kaspersky) retrieved 08 10, 2020, from https://ics-cert.kaspersky.com/

Kazemian, P., Chang, M., Zeng, H., Varghese, G., McKeown, N., Whyte, S. (2013). Real-time network policy checking using header space analysis. 10th USENIX Symposium on Networked Systems Design and Implementation (NSDI'13) (pp. 99111). USENIX association. Retrieved from https://www.usenix.org/system/files/conference/nsdi13/nsdi13-final8.pdf

Kazemian, P., Varghese, G., McKeown, N. (2012). Header space analysis: static checking for networks. 9th USENIX Symposium on Networked Systems Design and Implementation (NSDI'12) (pp. 1-14). USENIX association

Khodashenas, Aznar, J., Legarrea, A., Ruiz, M., Siddiqui, S., Escalona, E., Figuerola, S. (2016). 5 G network challenges and realisation insights. IEEE Xplore, 1-4. doi:https://doi.org/10.1109/ICTON.2016.7550539

Khurshid, A., Zou, X., Zhou, W., Caesar, M., Godfrey, P.B. (2013). Veriflow: verifying network-wide invariants in real-time. 10th USENIX Symposium on Networked Systems Design and Implementation (NSDI'13) (pp. 15-27). USENIX association

Kimani K, Oduol V, Langat K (2019) Cyber security challenges for loT based smart grid networks. Int J Crit Infrastruct Prot 25: 36-49. https://doi.org/10.1016/j.jicip.2019.01.001

Kochman, B. (2020). How criminals are exploiting the coronavirus outbreak. Retrieved from www.law360.com: https://www.la w360.com/cybersecurity-privacy/articles/1255130/how-cybercriminals-are-exploiting-the-coronavirus-outbreak

Kolias C, Kambourakis G, Stavrou A, Voas J (2017) DDoS in the loT: Mirai and other botnets. Computer 50(7):80-84. https://doi. org/10.1109/MC.2017.201

Kreyenberg, H. (2019). The energy sector as target of cyber attacks. HornetSecurty: Security Information. Retrieved from https://www.hornetsecurity.com/data/downloads/reports/document-cybersecurity-special-energy-en.pdf

Kumagai I (2012) Virtual power plants, real power, 5 kw here and $100 \mathrm{kw}$ there it all adds up

Kushner D (2013) The real story of Stuxnet. IEEE Spectrum Posted

Langill, J.T. (2014). Defending Against the Dragonfly Cyber Security Attacks. BELDEN. BELDEN. Retrieved 06 09, 2017

Langner, R., (2013). To Kill a Centrifuge - Technical Analysis of What Stuxnet's Creators tried to Achieve. The Langer group. Munich: the Langer group. Retrieved 06 11, 2017, from https://www.langner.com/wp-content/uploads/2017/03/to-kill-acentrifuge.pdf

Lathrop AJ, Stanisz HM (2016) Hackers are after more than just data: will your company property policies respond when cyberattacks cause physical damage and shut down operations? Environmental Claims J 28(4):286-303. https://doi.org/1 $0.1080 / 10406026.2016 .1197653$

Lee, R.M., Michael, J. A., Conway, T. (2016). Analysis of the Cyber Attack on the Ukrainian Power Grid Defense Use Case. SANS. Washington, DC: SANS. Retrieved 05 08, 2017, from https://ics.sans.org/media/E-ISAC_SANS_Ukraine_DUC_5.pdf

Leyden, J. (2012). Hack on Saudi Aramco hit 30,000 workstations, oil firm admits - First hacktivist-style assault to use malware? (TheRegister) retrieved 06 12, 2017, from http://www.theregister.co.uk/2012/08/29/saudi_aramco_malware_attack_analysis

Li, P., Liu, Y., Xin, H., Jiang, X. (2018). A robust distributed economic dispatch strategy of the virtual power plant under cyberattacks. IEEE Transactions on Industrial Informatics, 4343-4352

Liu, J., Xiao, Y., Li, S., Liang, W., Chen, C.L.P. (2012). Cyber security and privacy issues in smart grids. IEEE COMMUNICATIONS SURVEYS \& TUTORIALS, $14(4$, fourth quarter)

Lu R, Heung K, Lashkari A, Ghorbani AA (2017) A lightweight privacy-preserving data aggregation scheme for fog computing-enhanced loT. IEEE Access 5:3302-3312. https://doi.org/10.1109/ACCESS.2017.2677520

Mach P, Becavar Z (2017) Mobile edge computing a survey on architecture and computation offloading. IEEE Communications Surveys \& Tutorials 19(3):1628-1656. https://doi.org/10.1109/COMST.2017.2682318

Markham T, Payne C (2001) Security at the network edge: a distributed firewall architecture. DARPA Information Survivability Conference and Exposition II, DISCEX'01 (pp. 279-286). IEEE, Anaheim

McElroy, D., Williams, C. (2012). Flame: world's most complex computer virus exposed. (the telegraph) retrieved 06 12, 2017, from http://www.telegraph.co.uk/news/worldnews/middleeast/iran/9295938/Flame-worlds-most-complex-computervirus-exposed.html

Mcguinn MG (2004) Prioritising cyber vulnerabilities. Homeland Security, National Infrastructure Advisory Council. Homeland Security

McSherry, F., Talwar, K. (2007). Mechanism design via differential privacy. 48th Annual IEEE Symposium on Foundations of Computer Science (FOCS'07) (pp. 94-103). IEEE. doi:https://doi.org/10.1109/FOCS.2007.66

Miller, B., Rowe, D.C. (2012). A Survey of SCADA and Critical Infrastructure Incidents. Annual Conference on Research in Information Technology (pp. 51-56). New York, ISA: ACM

Mills, E. (2009). Report: Hackers have broken into the air traffic control mission-support systems of the U.S. Federal Aviation Administration several times in recent years. (ZDNet) retrieved 06 12, 2017, from http:/www.zdnet.com/news/report-us-a irtraffic-control-systems-hacked/300164 
Montero D (2015) Virtualised security at the network edge: a user-centric approach. IEEE Commun Mag 53(4):176-186. https://doi.org/10.1109/MCOM.2015.7081092

Montero, D., Serral-Gracia, R. (2016). Offloading personal security applications to the network edge: A mobile user case scenario. 2016 International conference on wireless communication and Mobile computing. IEEE

Moore, D., Paxson, V., Savage, S., Shannon, C., Staniford, S., Weaver, N. (2003). Inside the slammer worm. (IEEE, Ed.) IEEE Computer and Security, 99(4), 33-39. Retrieved 06 15, 2017, from http://cseweb.ucsd.edu/ savage/papers/IEEESP03.pdf

Mukherjee, B., Neupane, R., Calyam, P. (2017). End to end loT security middleware for cloud-fog communication. IEEE 4th International Conference on Cyber Security and Cloud Computing (pp. 151-156). New York, USA: IEEE. doi:https://doi. org/10.1109/CSCloud.2017.62

Nakashima, E., Miller, G., Tate, J. (2017, 06, 12). U.S., Israel developed Flame computer virus to slow Iranian nuclear efforts, officials say. (Washington post) retrieved 06 12, 2017, from https:/www.washingtonpost.com/world/national-security/usisrael-developed-computer-virus-to-slow-iranian-nuclear-efforts-officials-say/2012/06/19/gJQA6xBPoV_story.html

Nakashima, E., Warrick, J. (2012). Stuxnet was work of U.S. and Israeli experts, officials say. (Washington post) retrieved 0612 , 2017, from https:/www.washingtonpost.com/world/national-security/stuxnet-was-work-of-us-and-israeli-experts-officialssay/2012/06/01/gJQAlnEy6U_story.html

Naraine, R. (2010). Stuxnet attackers used 4 Windows zero-day exploits. (ZDNet) retrieved 06 12, 2017, from http://www.zdnet. $\mathrm{com} / \mathrm{blog} / \mathrm{security} /$ stuxnet-attackers-used-4-windows-zero-day-exploits/7347

Nelson, N. (2016). The Impact of Dragonfly Malware on Industrial Control Systems. SANS institute, SANS institute InfoSec Reading room. SANS. Retrieved 06 15, 2017, from https://www.sans.org/reading-room/whitepapers/ICS/impact-dragonflymalware-industrial-control-systems-36672

NewYork Times. (2012). Aramco Says Cyberattack Was Aimed at Production. (the Newyork Times) retrieved 06 12, 2017, from http://www.nytimes.com/2012/12/10/business/global/saudi-aramco-says-hackers-took-aim-at-its-production.html

Nunes R, Pontes R, Guedes D (2014) Virtualised network isolation using software defined networks (SDN). 38th Annual IEEE Conference on Local Computer Networks (pp. 683-686). IEEE, Sydney

Panda. (2015). Critical Infrastructure. Panda security. Retrieved from www.pandasecurity.com/mediacenter/src/uploads/2018/1 0/1611-WP-Criticallnfrastructure-EN.pdf

Pei D, Salomaa A, Ding C (1996) Chinese remainder theorem: applications. Computing, Coding, Cryptography - World Scientific Forum

Perlroth, N. (201210, 2,3). In Cyberattack on Saudi Firm, U.S. Sees Iran Firing Back. (the Newyork Times) retrieved 06 12, 2017 , from http://www.nytimes.com/2012/10/24/business/global/cyberattack-on-saudi-oil-firm-disquiets-us.html

Pop C, Antal M, Cioara T, Anghel I, Salomie I, Bertoncini C (2019) A fog computing enabled virtual power plant model for delivery of frequency restoration reserve services. Sensors, pp 1-20. https://doi.org/10.3390/s19214688

Poulsen, K. (2003). Slammer worm crashed Ohio nuke plant network. (SecurityFocus) retrieved 06 12, 2017, from http://www. securityfocus.com/news/6767

Poulsen, K. (2004). South Pole' cyberterrorist' hack wasn't the first. (TheRegister) retrieved 06 12, 2017, from http://www. theregister.co.uk/2004/08/19/south_pole_hack

Rausch, T., Dustdar, S. (2019). Edge intelligence: the convergence of humans, things, and a.l. 2019 IEEE International Conference on Cloud Engineering, IC2E (pp. 86-96). Prague, Chech Republic: IEEE

Razeghi, B., Voloshynovski, S. (2018). Privacy-preserving out-sourced media search using secure sparse ternary codes. 2018 IEEE International Conference on Acoustics, Speech and Signal Processing (ICASSP) (pp. 1992-1996). Calgary: IEEE. doi: https://doi.org/10.1109//CASSP.2018.8461862

Rene, M. $(2015,06,22)$. Hackers successfully ground 1,400 passengers. (CNN) retrieved 06 12, 2017, from http://edition.cnn. com/2015/06/22/politics/lot-polish-airlines-hackers-ground-planes/index.html

Rennie, M. (2019). Virtual Power Plants: On the Edge or the in the cloud. Retrieved from linkedin.com

Roman R, Rios R, Onieva J, Lopez J (2018) The immune system for the internet of things using edge technologies. IEEE Internet of Things Journal, pp 1-8

Sanger, D.E. (2012). Obama Order Sped Up Wave of Cyberattacks Against Iran. (the Newyork Times) retrieved 06 12, 2017, from http://www.nytimes.com/2012/06/01/world/middleeast/obama-ordered-wave-of-cyberattacks-against-iran.html

Sha K, Alatrash N, Wang A (2017) A secure and efficient framework to read isolated smart grid devices. IEEE Transactions on Smart Grid 8(6):2519-2531. https://doi.org/10.1109/TSG.2016.2526045

Sha K, Wang S, Shi W (2010) Rd4: role differentiated cooperative deceptive data detection and filtering in vanets. IEEE Trans Veh Technol 59(3):1183-1190

Sha K, Wei W, Yang A, Shi W (2016) Security in the internet of things: opportunities and challenges. International conference on identification, information and knowledge in the Internet of things (pp. 512-518). IEEE, Beijing. https://doi.org/10.1109/ ||KI.2016.35

Sha, K., Xi, Y., Shi, W, Schwiebert, L., Zhang, T. (2006). Adaptive privacy-preserving authentication in vehicular networks. 2006 First International Conference on Communications and Networking in China (pp. 1-8). Beijing, China: IEEE. doi:https://doi. org/10.1109/CHINACOM.2006.344746

Sha, K., Xu, C., Wang, Z. (2014). One-time symmetric key-based cloud supported secure smart meter reading. 2014 23rd International Conference on Computer Communication and Networks (ICCCN) (pp. 1-6). Shanghai: IEEE. doi:https://doi. org/10.1109/ICCCN.2014.6911854

Sha K, Yang AT, Wei W, Davari S (2020) A survey of edge computing-based designs for loT security. Digital communication networks 6(2):195-202. https://doi.org/10.1016/j.dcan.2019.08.006

Sha, K., Zeadally, S. (2015). Data quality challenges in cyber-physical systems. Journal of Data and Information Quality (JDIQ), 6(2-3). Doi:https://doi.org/10.1145/2740965

Sharma, S., Chen, K. (2017). Privategraph: a cloud-centric system for spectral analysis of large encrypted graphs. 2017 IEEE 37th International Conference on Distributed Computing Systems (ICDCS) (pp. 2507-2510). Atlanta, GA: IEEE. doi:https://doi.org/1 0.1109/ICDCS.2017.189

Singh, A., Auluck, N., Rana, O.F., Jones, A.C., Nepal, S. (2017). Rt-sane: real-time security-aware scheduling on the network edge. Proceedings of the 10th International Conference on Utility and Cloud Computing. doi:https://doi.org/10.1145/314 7213.3147216 
sKyWiper Analysis Team. (2012). sKyWIper (a.k.a. Flame a.k.a. Flamer - A complex malware for targeted attacks. Budapest University of Technology and Economics, Department of Telecommunications. Budapest: Laboratory of Cryptography and System Security (CrySyS Lab). Retrieved 06 11, 2017, from http://www.bme.hu/

Sweeney L (2002) K-anonymity: a model for protecting privacy. Int J Uncertainty, Fuzziness and Knowledge-based Systems 10(5):557-570. https://doi.org/10.1142/S0218488502001648

Symantec Corp. (2009). Symantec global internet security threat report trends. Symantec

Symantec Corp. (2011). Internet security threat report. Symantec

Symantec Corp. (2014). Security Response - Dragonfly: Cyberespionage Attacks Against Energy Suppliers. Symantec Labs, Symantec Labs. Symantec. Retrieved 06 11, 2017

Symantec Corp. (2018). Shamoon: Destructive Threat Re-Emerges with New Sting in its Tail. (Symantec response team) retrieved 08 04, 2019, from Symantec: https://www.symantec.com/blogs/threat-intelligence/shamoon-destructive-threatre-emerges-new-sting-its-tail

Symantec Crop. (2017). Shamoon: Multi-staged destructive attacks limited to specific targets. (Symantec Labs) retrieved 0608 , 2017, from https://www.symantec.com/connect/blogs/shamoon-multi-staged-destructive-attacks-limited-specific-targets

Tao X, Ota K, Dong M, Qi H, Li K (2017) Performance guaranteed computation offloading for mobile edge cloud computing IEEE Wireless Communication Letters 6(6):774-777. https://doi.org/10.1109/LWC.2017.2740927

Thomson, L. (2013). Snowden: U.S. and Israel did create Stuxnet attack code. (TheRegister) retrieved 06 12, 2017, from http:// www.theregister.co.uk/2013/07/08/snowden_us_israel_stuxnet

Tian L, Li J, Li W, Ramesh B, Cai Z (2019) Optimal contract-based mechanisms for online data trading markets. IEEE Internet Things J 6(5):7800-7810. https://doi.org/10.1109/JIOT.2019.2902528

Trend Micro. (2018). New Version of Disk-Wiping Shamoon/Disttrack Spotted What you need to know. (T. Micro, producer) retrieved 08 04, 2019, from trend Micro: https://www.trendmicro.com/vinfo/hk-en/security/news/cybercrime-and-digitalthreats/new-version-of-disk-wiping-shamoon-disttrack-spotted-what-you-need-to-know

Tsai H (2012) Treat as a service: Virtualisations impact on cloud security. I.T. Professional 14(1):32-37. https://doi.org/10.1109/ MITP.2011.117

Venkatachary SK, Prasad J, Samikannu R (2017) Economic impacts of cyber security in energy sector: a review. (IJEEP, Ed.). Int J Energy Econ Policy 7(5):250-262 Retrieved from www.econjournals.com

Venkatachary SK, Prasad J, Samikannu R (2018a) A critical review of cyber security and cyber terrorism - threats to critical infrastructure in the energy sector. International Journal of Critical Infrastructures 14(2):101-119

Venkatachary, S.K., Prasad, J., Samikannu, R. (2018b). Cyber security and cyber terrorism in energy sector - a review. Journal of Cyber Security Technology, 2(3-4), 111-130. doi:https://doi.org/10.1080/23742917.2018.1518057

Venkatachary SK, Prasad J, Samikannu R, Alagappan A, Andrews LJB (2020) Cybersecurity infrastructure challenges in loT based virtual power plants. Journal of Statistics and Management Systems 23(2):263-276. https://doi.org/10.1080/0972051 0.2020 .1724625

Wang Z, Sha K, Lv W (2013) Slight homomorphic signature for access controlling in cloud computing. Wirel Pers Commun 73(1):51-61. https://doi.org/10.1007/s11277-012-0977-8

Weber RH, Studer E (2016) Cybersecurity in the internet of things: legal aspects. Comput Law Secur Rev 32(5):715-728. https://doi.org/10.1016/j.clsr.2016.07.002

Wilhoit, K. (2013). Who's really attacking your ICS equipment? Retrieved 11 28, 2020, from www.trendmicro.com: https://www. trendmicro.com.tr/media/wp/whos-really-attacking-your-ics-equipment-whitepaper-en.pdf

Xi, Y., Sha, K., Shi, W., Schwiebert, L., Zhang, T. (2007). Enforcing privacy using symmetric key-set in vehicular networks. Eighth International Symposium on Autonomous Decentralized Systems (ISADS'07) (pp. 344-351). Sedona: IEEE

Yaseen, Q., Al-Balas, F., Jararweh, Y., Al-Ayyoub. (2016). A FOG computing-based system for selective forwarding detection in mobile wireless sensor networks. 2016 IEEEE 1st International Workshop on Foundations and Applications of Self* Systems (pp. 256-262). Augsburg: IEEE doi:https://doi.org/10.1109/FAS-W.2016.60

Yin C, Zhu Y, Fei J, He X (2017) A deep learning approach for intrusion detection using recurrent neural networks. IEEE Access 5:21954-21961. https://doi.org/10.1109/ACCESS.2017.2762418

Zaho, Q., Gerla, M. (2019). Energy efficiency enhancement in 5 G mobile networks. IEEE 20th International Symposium on a world of wireless mobile and multimedia networks (pp. 1-3). Washington, USA: IEEE explore

Zakhmatov, V.D., Glushkova, V.V., Kryazhich, O.A. (2011). Explosion, Which was not. Retrieved from ogas.kiev.ua: http://ogas. kiev.ua/perspective/vzryv-kotorogo-ne-bylo-581

Zhou, Z., Chen, X., Li, E., Zeng, L., Luo, K., Zhang, J. (2019). Edge intelligence: paving the last mile of artificial intelligence with edge computing. Proc. IEEE, 1738-1762

\section{Publisher's Note}

Springer Nature remains neutral with regard to jurisdictional claims in published maps and institutional affiliations. 